\title{
Analgesic, Anti-inflammatory, and Anti-pyretic Activities of Crinum pedunculatum R.Br. Bulb Extracts
}

\author{
Peace Doe ${ }^{1,2, *}$, Cynthia Amaning Danquah ${ }^{1}$, Kwasi Adomako Ohemeng ${ }^{3}$, Ako Ernest Opare ${ }^{2}$, Ahmed Sharif ${ }^{2}$, \\ Dorcas Akua-Abora², Asamoah Kwame Akuoko², Aaron Kpabitey², Emmanuel Quarshie², Oliver Opoku Asante², \\ Elvis Kwadwo Amponsah², Mariyana Mutwaliku'², Charlotte Nuro-Brefo' ${ }^{2}$, Micheal Ofori ${ }^{1}$
}

\section{Peace Doe ${ }^{1,2, *}$, Cynthia Amaning Danquah ${ }^{1}$, Kwasi Adomako Ohemeng ${ }^{3}$, Ako Ernest Opare ${ }^{2}$, Ahmed Sharif ${ }^{2}$, Dorcas Akua-Abora², Asamoah Kwame Akuoko², Aaron Kpabitey², Emmanuel Quarshie, Oliver Opoku Asante2, Elvis Kwadwo Amponsah², Mariyana Mutwaliku², Charlotte Nuro-Brefo Micheal Ofori ${ }^{1}$ \\ 'Department of Pharmacology, Faculty of Pharmacy and Pharmaceutical Sciences, Kwame Nkrumah University of Science and Technology, GHANA. \\ 'Department of Pharmaceutical Sciences, School of Pharmacy, Central University, GHANA. \\ ${ }^{3}$ Department of Medicinal Chemistry, School of Pharmacy, Central University, GHANA. \\ Correspondence \\ Peace Doe}

Department of Pharmaceutical Sciences, School of Pharmacy. Central University Ghana. P. O. Box 2305, Tema, GHANA. Email id: pdoe@central.edu.gh

History

- Submission Date: 11-10-2021;

- Review completed: 06-11-2021;

- Accepted Date: 09-12-2021.

DOI : 10.5530/pres.14.1.5

Article Available online

http://www.phcogres.com

Copyright

(C) 2022 Phcog.Net. This is an openaccess article distributed under the terms of the Creative Commons Attribution 4.0 International license.

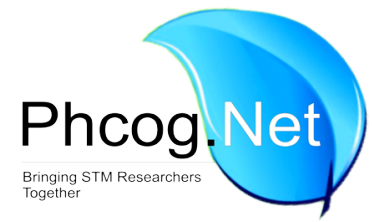

\begin{abstract}
Background: Crinum pedunculatum R.Br. bulbs are used for the topical management of inflammation by traditional healers in the southern region of Ghana. Objectives: This study aims to assess the analgesic, anti-inflammatory, and anti-pyretic activities of different solvent extracts of Crinum pedunculatum. Methods: The analgesic, anti-inflammatory, and anti-pyretic activities of the bulb extracts of Crinum pedunculatum were determined in rats at doses of 100,200 , and $400 \mathrm{mg} / \mathrm{kg}$. The acetic acid induced writhing test was used to determine the analgesic activity, carrageenan was employed to determine the anti-inflammatory activity, and Brewer's yeast-induced pyrexia was studied to evaluate the extract's anti-pyretic activity. Results: All solvent extracts of Crinum pedunculatum significantly decreased $(P<0.001)$ the frequency of writhing in rats at all doses with $400 \mathrm{mg} / \mathrm{kg}$ of the ethanolic extract showing a $98 \%$ inhibition comparable to that obtained with diclofenac sodium at $94 \%$. These extracts also caused the inhibition of the increase in paw diameter induced by the administration of carrageenan with $400 \mathrm{mg} / \mathrm{kg}$ of the ethyl acetate extract of Crinum pedunculatum causing a $97 \%$ inhibition of paw oedema. All doses $(100,200$, and $400 \mathrm{mg} / \mathrm{kg}$ ) of the methanol extract caused a significant decrease $(P<0.0001)$ in the temperature of rats induced via the administration of yeast with ethanol and ethyl acetate extracts also showed a significant reduction $(P<0.001)$ in rectal temperature. Conclusion: These results obtained indicate that the methanolic, ethanolic, and ethyl acetate extracts of Crinum pedunculatum R.Br. possess analgesic, anti-inflammatory, and antipyretic activities.
\end{abstract}

Key words: Analgesic, Anti-inflammatory, Anti-pyretic, Crinum pedunculatum, Rats.

\section{INTRODUCTION}

Several disease conditions are routinely present with pain and pyrexia. Nonsteroidal anti-inflammatory drugs (NSAIDS) are frequently prescribed to manage these conditions, but gastrointestinal bleeding, perforation, exacerbation of gastric ulcers and cardiac irregularities are some of the side effects associated with their use. ${ }^{[1]}$ Natural products and their derivatives are principal sources for the management of several diseases worldwide. ${ }^{[2]}$ The scientific investigation of plants used as analgesics, anti-inflammatory, and antipyretic agents in traditional medicine is a strategy that has yielded and will continue to yield promising prospects. Crinum species have a substantial medicinal reputation as potent traditional remedies with their use extending to present times in Africa, tropical Asia, and South America. ${ }^{[3,4]}$ They are used traditionally as emetics, laxatives, expectorants, antipyretics, among others. Extracts of Crinum species have been reported to possess cytotoxic, antitumor, antiviral, antimicrobial, antimalarial, analgesic, and immunomodulating

activities. These activities have been attributed to the presence of alkaloids in these Crinum species. ${ }^{[5-9]}$

Crinum pedunculatum, also known as swamp lily, belongs to the family Amaryllidaceae. Plants of the Crinum species have been reported to contain phytoconstituents such as coumarins, catechic tannins, triterpenes, anthocyanidins, polyphenols among others. ${ }^{[10]}$ The bulbs of Crinum pedunculatum plant are used by traditional healers of the southern region of Ghana for the management of inflammation, pain, and fever. However, there are no scientific studies carried out to validate these activities and to the best of our knowledge no pharmacologic or biologic evaluations of any activities concerning this plant have been reported. Consequently, this study was carried out to evaluate the analgesic, anti-inflammatory, and anti-pyretic activities of the methanolic, ethanolic, and ethyl acetate extracts of the bulbs of Crinum pedunculatum. 


\section{MATERIALS AND METHODS}

\section{Plant collection and identification}

Bulbs of Crinum pedunculatum were collected from Oframatin, Kwahu-Asakrakra in the Eastern region of Ghana (Latitude: 6.62942 N 6 37 '45.9048”. Longitude:-0.68647 W 041'11.30253"). They were identified and authenticated by Mr Clifford Asare, an herbalist at the Herbal Medicine Department, Faculty of Pharmacy and Pharmaceutical Sciences (FPPS), Kwame Nkrumah University of Science and Technology, Ghana. A sample was kept at the herbarium (voucher specimen number $\mathrm{CP} / 01 / 19$ ) of Central University, Ghana, where part of the research was carried out.

\section{Plant preparation and extraction}

The dried bulbs were ground into coarse powder and extracted with 99.8\% ethanol, 99.8\% methanol, and ethyl acetate using cold maceration method. The preparation was shaken intermittently for 7 days, after which filtration through a No. 1 Whatman filter paper was carried out. A rotary evaporator was used to evaporate the solvents, and the dried extracts were stored in separate air-tight containers and refrigerated at $4^{\circ} \mathrm{C}$ for use.

\section{Experimental animals}

Wistar albino rats weighing 93-110 g obtained from the University of Ghana animal house were used in this study. They were allowed to acclimatize for 14 days. Animals were kept in plastic cages and fed with a standard pellet diet and granted unrestrained access to clean water. All experimental protocols and handling of animals were carried out in compliance with the Institute for Laboratory Animal Research ${ }^{[11]}$ and were authorized by the Institutional Review Board on Animal Experimentation, Kwame Nkrumah University of Science and Technology with the ethics reference number FPPS/PCOL/010/2019.

\section{Phytochemical screening}

Preliminary phytochemical analysis was conducted on the methanolic, ethanolic, and ethyl acetate extracts of Crinum pedunculatum using standard methods described by Trease and Evans. ${ }^{[12]}$ Qualitative screening was carried out for tannins, phlobatannins, flavonoids, saponins, cardiac glycosides, and alkaloids.

\section{Acute toxicity test}

Acute toxicity test was performed on the methanol, ethanol, and ethyl acetate extracts of Crinum pedunculatum following the guidelines stated by The Organization for Economic and Co-operative Development. ${ }^{[13]}$

\section{Analgesic activity}

\section{Acetic acid induced writhing test}

The method described by Koster et al ${ }^{[14]}$ with some adjustment was employed to determine the analgesic effect of the crude extracts in rats. Experimental animals were weighed and distributed into 5 groups of 5 animals each. Group 1 served as the negative control and were administered normal saline $10 \mathrm{ml} / \mathrm{kg}$, group 2 received diclofenac $75 \mathrm{mg} / \mathrm{kg}$ (standard drug), while groups 3, 4, and 5 received Crinum pedunculatum extracts at 100, 200 and $400 \mathrm{mg} / \mathrm{kg}$ respectively. All administrations were done orally. Thirty minutes after pretreatment, each animal received $1 \%$ acetic acid $(10 \mathrm{ml} / \mathrm{kg})$ intraperitoneally. Frequency of abdominal writhes were counted for 15 min commencing 5 min following acetic acid administration. Percentage of analgesic activity was determined using the following formula:
Percentage inhibition of writing $=\left[\frac{W_{\text {control }}-W_{\text {treated }}}{W_{\text {control }}} \times 100\right]$

Where $\mathrm{W}=$ number or frequency of writhes

\section{Anti-inflammatory activity}

Carrageenan-induced rat paw oedema

Anti-inflammatory activity was carried out using Wistar rats according to the method reported by Winter et al. ${ }^{[16]}$ Group 1 served as the negative control and were administered normal saline $10 \mathrm{ml} / \mathrm{kg}$, group 2 (positive control) received diclofenac $75 \mathrm{mg} / \mathrm{kg}$ (standard drug), and groups 3, 4 and 5 were administered 100, 200 and $400 \mathrm{mg} / \mathrm{kg}$ of Crinum pedunculatum extract respectively. One hour following pretreatment, inflammation was induced by the administration of $0.1 \mathrm{ml}$ carrageenan $(1 \% \mathrm{w} / \mathrm{v})$ in $0.9 \%$ normal saline to the right hind paw of each animal by sub-plantar injection. Diameter of the injected paw was measured every hour for $6 \mathrm{hr}$ using digital callipers. Percentage reduction in diameter of the treated group was calculated as follows: ${ }^{[17]}$

Percentage reduction in paw diameter $=\left[\frac{(C t-C o) \text { control }-(C t-C o) \text { treated }}{(C t-C o) \text { control }} \times 100\right]$

Where $\mathrm{C}_{\mathrm{t}}=$ paw diameter at time $\mathrm{t} ; \mathrm{C}_{0}=$ paw diameter before carrageenan injection.

\section{Anti-pyretic Activity}

Anti-pyretic activity was determined in rats using Brewer's yeast following standard procedures. ${ }^{[18,19]}$ The basal rectal temperature of each animal was taken using a clinical digital thermometer, after which pyrexia was induced by the subcutaneous injection of $20 \% \mathrm{w} / \mathrm{v}$ Brewer's yeast suspension in normal saline at $10 \mathrm{ml} / \mathrm{kg}$ of rat. Increase in rectal temperature of each animal was recorded $18 \mathrm{hr}$ after yeast injection and animals that showed a rise in temperature of $\geq 1 \mathrm{~F}\left(0.6^{\circ} \mathrm{C}\right)$ were chosen for the study. Animals were subsequently distributed into five groups of 5 animals with group 1 receiving $10 \mathrm{ml} / \mathrm{kg}$ normal saline, group 2 receiving $125 \mathrm{mg} / \mathrm{kg}$ paracetamol, groups 3, 4, and 5 receiving 100, 200 and $400 \mathrm{mg} / \mathrm{kg}$ of Crinum pedunculatum extract respectively. Rectal temperature of each rat was recorded for the first $6 \mathrm{hr}$ and at 12 and $24 \mathrm{hr}$ to confirm activity of the extract.

\section{Statistical analysis}

All results are expressed as mean \pm standard error of the mean (SEM). Results were analysed statistically using GraphPad prism version 8 software and $P<0.05$ was regarded as statistically significant.

\section{RESULTS}

Phytochemical analysis of Crinum pedunculatum extracts indicated the presence of saponins, alkaloids, and phlobatannins among others (Table 1).

\section{Acute toxicity test}

Acute toxicity experiments carried out with all Crinum pedunculatum extracts showed that the limit dose of $2000 \mathrm{mg} / \mathrm{kg}$ did not result in mortality and any visible toxic manifestations such as changes in skin, fur, eyes, respiration, tremors, convulsions, salivation, diarrhoea, sleep and lethargy.

\section{Acetic acid induced writhing test}

All doses of the ethanolic, methanolic, and ethyl acetate extracts of Crinum pedunculatum (100, 200, and $400 \mathrm{mg} / \mathrm{kg}$ ) exhibited significant decrease in the number of writhes induced by acetic acid relative to the 
Table 1: Phytochemical analysis of Crinum pedunculatum extracts.

\begin{tabular}{cccc}
\hline \multicolumn{4}{c}{ Crinum pedunculatum extracts } \\
\hline $\begin{array}{c}\text { Phytochemical } \\
\text { Constituent }\end{array}$ & Methanol extract & $\begin{array}{c}\text { Ethanol } \\
\text { extract }\end{array}$ & $\begin{array}{c}\text { Ethyl acetate } \\
\text { extract }\end{array}$ \\
\hline Saponins & + & + & + \\
Alkaloids & + & + & + \\
Phlobatannins & + & - & + \\
Phenols & - & + & - \\
Flavonoids & - & + & - \\
Tannins & - & + & - \\
Cardiac glycosides & - & + & - \\
Steroids & - & - & + \\
Reducing sugar & + & + & - \\
Oil & + & + & - \\
Carbohydrates & - & - & + \\
\hline
\end{tabular}

$+=$ present; - = absent

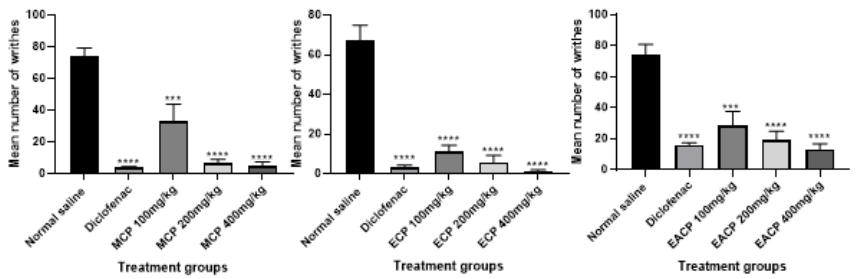

Figure 1: The effect of methanol (MCP), ethanol (ECP), and ethyl acetate (EACP) extracts of Crinum pedunculatum on acetic acid induced writhing. ${ }^{* * *} P<0.001,{ }^{* * *} P<0.0001$ relative to the control (One-way ANOVA followed by Dunnett's multiple comparison test).

Table 2: The percentage inhibition of different extracts of Crinum pedunculatum.

\begin{tabular}{ccc}
\hline Treatment groups & Dose $(\mathrm{mg} / \mathrm{kg})$ & $\begin{array}{c}\text { Percentage inhibition of } \\
\text { writhes (\%) }\end{array}$ \\
\hline Normal saline & 10 & 0 \\
Diclofenac sodium & 75 & 93.75 \\
Methanolic extract & 100 & 30.1 \\
& 200 & 86.11 \\
Ethanolic extract & 400 & 90.28 \\
& 100 & 84.44 \\
& 200 & 91.94 \\
Ethyl acetate extract & 400 & 98.06 \\
& 100 & 60.28 \\
& 200 & 73.61 \\
& 400 & 81.39 \\
\hline
\end{tabular}

$\operatorname{control}\left(\mathrm{F}_{4,20}=29.50, P<0.0001\right),\left(\mathrm{F}_{4,20}=44.73, P<0.0001\right),\left(\mathrm{F}_{4,20}=17.79\right.$, $P<0.0001)$ respectively. The most significant $(P<0.0001)$ reduction was observed with the methanolic, ethanol and ethyl acetate extracts at doses $200 \mathrm{mg} / \mathrm{kg}$ and $400 \mathrm{mg} / \mathrm{kg}$ (Figure 1). The percentage inhibition of writhing of the ethanolic extract at 100 and $200 \mathrm{mg} / \mathrm{kg}$ are $84.44 \%$ and $91.94 \%$, respectively, with the $400 \mathrm{mg} / \mathrm{kg}$ dose showing the highest inhibition at $98.06 \%$ (Table 2).
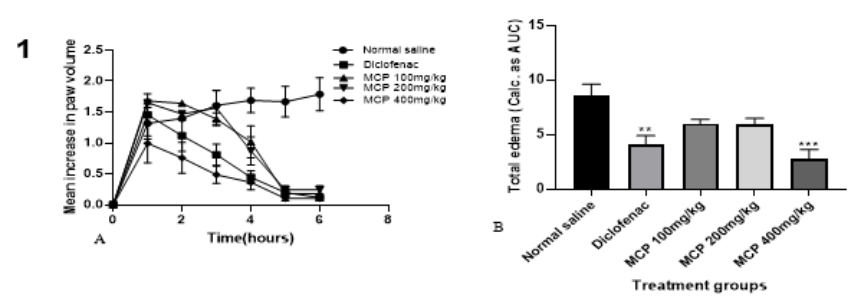

2
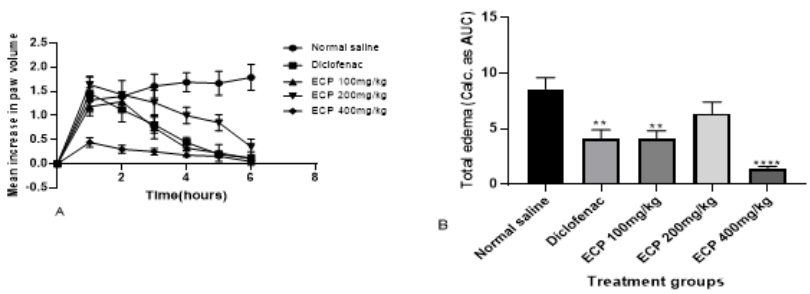

3

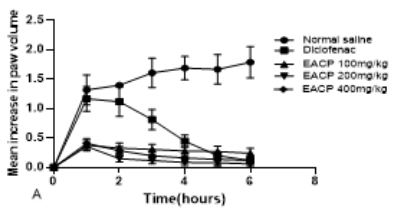

Figure 2: The effect of MCP-methanol, ECP-ethanol, and EACP-ethyl acetate extracts of Crinum pedunculatum on mean increase in paw diameter $(A)$ and total oedema (B) (calculated as AUC) in carrageenan-induced paw inflammation. ${ }^{* *} P<0.01,{ }^{* * *} P<0.001,{ }^{* * * *} P<0.0001$ relative to the control (One-way ANOVA followed by Dunnett's multiple comparison test).

\section{Carrageenan-induced inflammation in rats}

Oral administration of methanol, ethanol, and ethyl acetate extracts of Crinum pedunculatum showed anti-inflammatory activity by significantly decreasing paw oedema induced by carrageenan (Figure 2). The protection from inflammation exhibited by the ethanol extract was non-dose dependent with $100 \mathrm{mg} / \mathrm{kg}$ of the ethanol extract showing better protection than $200 \mathrm{mg} / \mathrm{kg}$ and $400 \mathrm{mg} / \mathrm{kg}$ showing the highest protection. Although all doses of the ethyl acetate extract showed significant inhibition of inflammation, a ceiling effect was observed at $200 \mathrm{mg} / \mathrm{kg}$. The methanol extract at $400 \mathrm{mg} / \mathrm{kg}$ showed a significant reduction $(P<0.0001)$ in paw diameter from the first to the sixth hour compared to the negative (normal saline) and positive control (diclofenac).

\section{Brewer's yeast-induced pyrexia}

Rectal temperature was recorded for each animal every hour for $6 \mathrm{hr}$ after the administration of different solvent extracts of Crinum pedunculatum as well as the standard drug paracetamol. All doses of the methanol and ethyl acetate extracts showed significant reduction of rectal temperature ( $P<0.0001$ and $P<0.001)$, which was not dose-dependent. The ethanol extract at the dose of 200 and $400 \mathrm{mg} / \mathrm{kg}$ caused significant reduction in temperature $(P<0.0001$ and $P<0.001)$, but a ceiling effect was observed at $200 \mathrm{mg} / \mathrm{kg}$ (Figure 3).

\section{DISCUSSION}

Efforts made to develop new, efficacious and relatively safe agents for the management of inflammation are still necessary today to find an alternative to the use of NSAIDs. Natural product drug discovery remains 
1
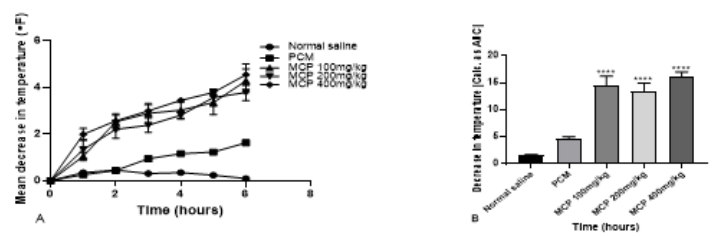

2
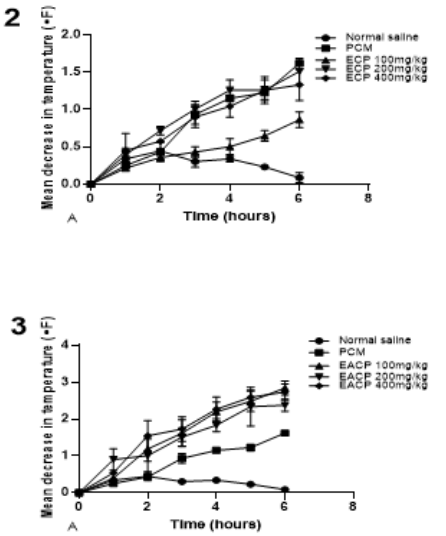
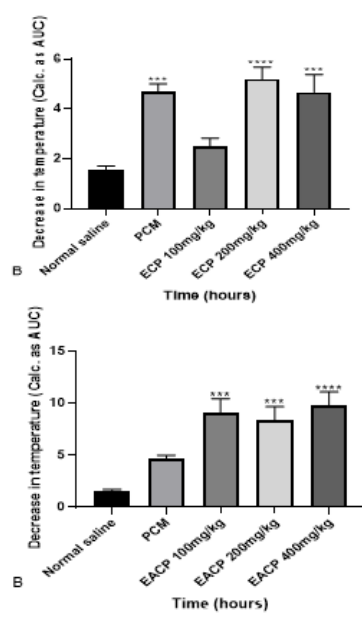

Figure 3: The effect of MCP-methanol (1), ECP-ethanol (2), and EACP-ethyl acetate (3) extracts of Crinum pedunculatum on the change in rectal temperature (A) and total decrease in temperature (B) (calculated as AUC) on brewer's yeast-induced pyrexia. ${ }^{* * *} P<0.001,{ }^{* * *} P<0.0001$ relative to the control (One way ANOVA followed by Dunnett's multiple comparison test).

a major contributor to the development of novel therapeutic agents. ${ }^{[20]}$ This study was carried out to evaluate the analgesic, anti-inflammatory, and antipyretic activities of the bulbs of Crinum pedunculatum, family Amaryllidaceae. Acute toxicity experiments showed no mortality all the extracts at $2000 \mathrm{mg} / \mathrm{kg}$. Analgesic activity was determined by intraperitoneal injection of acetic acid, which results in contortions of the animal's abdominal muscle (writhing) along with the stretching of the hind limbs, and these reactions are considered to be caused by local peritoneal receptors. ${ }^{[21]}$ In the acetic acid-induced model, several cytokines are released like interleukin $1 \beta$, tumour necrosis factor $\alpha$, and chemokines which act together to induce writhing. ${ }^{[22,23]}$ Furthermore, several studies have shown elevated levels of prostaglandins, mainly PGF2 $\alpha$, PGE2, PGI2 in the peritoneal fluids of animals administered with acetic acid ${ }^{[24,25]}$ and NSAIDs have been established to alleviate pain by inhibiting the synthesis of prostaglandins along with several inflammatory mediators by inhibiting these cyclooxygenase enzymes. ${ }^{[26]}$ Therefore, any substance that causes a reduction in the frequency of abdominal writhes induced by acetic acid can be postulated to possess analgesic effect. The methanol, ethanol, and ethyl acetate extracts of Crinum pedunculatum significantly decreased the frequency of abdominal writhes in a dose-dependent form (Figure 1). It can be postulated that the analgesic activity observed by the extracts could be due to the inhibition of the pathway involved in the synthesis of prostaglandins as well as the local inhibition of peritoneal inflammation. Carrageenan-induced hind paw oedema was employed to investigate the anti-inflammatory activity of Crinum pedunculatum. Oedema induced by carrageenan is regarded as the initial phase of the process of inflammation and is characterized by fluid and cell exudation.

${ }^{[27]}$ The development of oedema in the hind paws of the animal after carrageenan administration is caused initially by the release of mediators like histamine and serotonin and subsequently by prostaglandins which further facilitates the oedema. ${ }^{[27-29]}$ This study showed that the standard drug diclofenac caused the inhibition of paw oedema from the $3^{\text {rd }}$ to the final hour, which is consistent with its mechanism of action. Diclofenac acts by inhibiting cyclooxygenase- 1 and 2 enzymes, thereby inhibiting the synthesis of prostaglandins released during the late phase after carrageenan administration. ${ }^{[30,31]}$ All doses of the ethyl acetate extracts showed a significant decrease in paw diameter from the first hour after carrageenan administration; 200 and $400 \mathrm{mg} / \mathrm{kg}$ of the methanol extract as well as 100 and $400 \mathrm{mg} / \mathrm{kg}$ of the ethanol extract also showed significantly lower paw diameter compared to the negative control. (Figure 2). The highest and most significant inhibition of the increase in paw oedema caused by carrageenan was observed at the fourth hour for all solvent extracts of Crinum pedunculatum (Figure 2). It can be postulated that the ethanol, methanol, and ethyl acetate extracts of Crinum pedunculatum inhibit fluid exudation, as well as several mediators of inflammation such as serotonin and histamine that contribute to the acute inflammatory process. Further studies are required to determine the specific inflammatory mediators inhibited by these extracts.

The extracts were also evaluated for antipyretic activity using Brewer's yeast model which is associated with fever through an inflammatory reaction $^{[32]}$ caused by the synthesis of pro-inflammatory cytokines like interleukin- $1 \beta$ and interleukin-6, interferon- $\alpha$, tumour necrosis factor $\alpha$ and prostaglandins E2 and I2. These mediators are responsible for causing an increase in body temperature through their action on the brain. ${ }^{[33,34]}$ Antipyretic agents like paracetamol, used as a standard drug in this study, exert their effects by decreasing prostaglandin synthesis through the inhibition of cyclooxygenase enzymes as well as by activating anti-inflammatory signals at the site of tissue damage. ${ }^{[35]}$ The methanol, ethanol, and ethyl acetate extracts all showed a significant reduction in temperature induced by the administration of yeast (Figure 3), which could be as a result of the inhibition of pro-inflammatory cytokines.

Phytochemical analysis was carried out on all extracts of Crinum pedunculatum used in this study. Flavonoids, alkaloids, tannins, and saponins were found to be present in these extracts (Table 1) and several studies have described the analgesic, antipyretic, and anti-inflammatory activities of these constituents. ${ }^{[36-39]}$ It can therefore be postulated that the analgesic, anti-inflammatory, and anti-pyretic activities observed by the methanol, ethanol, and ethyl acetate extracts of Crinum pedunculatum may be due to the presence of these phytochemical constituents.

\section{CONCLUSION}

This study showed that the methanol, ethanol, and ethyl acetate extracts of the bulbs of Crinum pedunculatum R.Br. possess significant peripheral analgesic, anti-inflammatory and antipyretic activities justifying their use by traditional healers in the southern regions of Ghana. Further studies are ongoing to isolate and characterize compounds that are responsible for these observed activities to offer new leads for the development of agents with analgesic, anti-inflammatory, and antipyretic effects.

\section{ACKNOWLEDGEMENT}

The authors are grateful to Mr Kwame Koomson for his technical assistance all through the research as well as Mr Kevin Fiati for his help with the phytochemical screening. 


\section{Author Contributions}

PD and CAD: Conceptualization, Methodology, Literature search; PD, AEO, AS, DAA and AKA: Experimental Studies and data analysis for the methanolic extract of Crinum pedunculatum, PD, AK, EQ and OOA: Experimental studies and data analysis involving the ethyl acetate extract of Crinum pedunculatum. PD, EKA, MM and CNB: Experimental studies and data analysis involving the ethanol extract of Crinum pedunculatum. PD, CAD and KAO: Data analysis, Statistical analysis Manuscript preparation, editing and reviewing. CAD and KAO: Supervision. Guarantor: Peace Doe. All authors have read and approved the final version of the manuscript.

\section{CONFLICT OF INTEREST}

The authors declare no conflict of interest

\section{ABBREVIATIONS}

NSAIDS: Nonsteroidal anti-inflammatory drugs; OECD: Organization for Economic and Co-operative Development; IP: Intraperitoneal Administration; PGE2: Prostaglandin E2; PGI2: Prostaglandin I2; PGF2 $\alpha$ : Prostaglandin F2 $\alpha$.

\section{SUMMARY}

Natural plants still provide important source of new compounds and potential drugs. Since these plants are employed by traditional healers in Ghana, it is imperative to provide scientific basis for their use and this has informed this study. All solvent extracts of Crinum pedunculatum investigated in this study possess analgesic, anti-inflammatory and antipyretic activities justifying their use.

\section{REFERENCES}

1. Ofman JJ, MacLean $\mathrm{CH}$, Straus WL, Morton SC, Berger ML, Roth EA, et al. A metaanalysis of severe upper gastrointestinal complications of nonsteroida anti-inflammatory drugs. J Rheumatol. 2002;29(4):804-12. PMID 11950025.

2. Kiringe JW. A survey of traditional health remedies used by the Maasai of Southern Kaijiado District, Kenya. Ethnobot Res Appl. 2006 Dec 31;4:061. doi: 10.17348/era.4.0.61-74.

3. Author. A, Snijman DA, Linder HP. Phylogenetic relationships, seed characters, and dispersal system evolution in. Vol. 83. Source. Annals Publishing of the Missouri Botanical Garden. 1996.

4. Fennell CW, Van Staden J. Crinum species in traditional and modern medicine. J Ethnopharmacol. 2001 Nov 1;78(1):15-26. doi: 10.1016/s0378-8741(01)00305-1, PMID 11585683

5. Jenny M, Wondrak A, Zvetkova E, Tram NTN, Phi PTP, Schennach H, et al. Crinum latifolium leave extracts suppress immune activation cascades in peripheral blood mononuclear cells and proliferation of prostate tumor cells. Sci Pharm. 2011 Apr 5;79(2):323-35. doi: 10.3797/scipharm.1011-13, PMID 21773069

6. Presley CC, Krai P, Dalal S, Su Q, Cassera M, Goetz M, et al. New potently bioactive alkaloids from Crinum erubescens. Bioorg Med Chem. 2016;24(21):5418-22. doi: 10.1016/j.bmc.2016.08.058, PMID 27624525.

7. Aziz A, Sarwar Raju GS, Das A, Ahmed J, Moghal MMR. Evaluation of in vitro anthelmintic activity, total phenolic content and cytotoxic activity of Crinum latifolium L. (Family: Amaryllidaceae). Adv Pharm Bull. 2014;4(1):15-9. doi: 10.5681/apb.2014.003, PMID 24409404

8. Presley CC, Du Y, Dalal S, Merino EF, Butler JH, Rakotonandrasana S, et al Isolation, structure elucidation, and synthesis of antiplasmodial quinolones from Crinum firmifolium. Bioorg Med Chem. 2017;25(15):4203-11. doi: 10.1016/j. bmc.2017.06.017, PMID 28648491.

9. Zvetkova E, Wirleitner B, Tram NT, Schennach H, Fuchs D. Aqueous extracts of Crinum latifolium (L.) and Camellia sinensis show immunomodulatory properties in human peripheral blood mononuclear cells. Int Immunopharmacol. $2001 \mathrm{Nov}$ 1;1(12):2143-50. doi: 10.1016/s1567-5769(01)00140-0, PMID 11710543.

10. Mvongo C, Noubissi PA, Kamgang R, Minka Minka CS, Mfopa A, Oyono J-LE. Phytochemical studies and in vitro antioxidant potential of two different extracts of crinum JAGUS. Int J Pharm Sci Res. 2015;6(6):2354-9.

11. National Research Council. Guide for the care and use of laboratory animals Eighth. In: National Academies Press, editor. Guide for the care and use of laboratory animals. National Academies Press; 2011. p. 11-21.
12. Evans WC, Trease GE. Trease and Evans' pharmacognosy e-book [internet]. Saunders Ltd; 2009. Sixteenth [cited May 14 2019].

13. Organization for Economic Co-operation and Development. Test No. 423 acute Oral toxicity - Acute Toxic Class Method. OECD Guidel Test Chem. 2002 (Dec):1-14.

14. Koster R, Anderson M, De Beer EJ. Acetic acid for analgesic screening. Fed Proc. 1959;18:412-8.

15. Subedi NK, Rahman SM, Akbar MA. Analgesic and antipyretic activities of methanol extract and its fraction from the root of Schoenoplectus grossus. Evid Based Complement Alternat Med. 2016;2016:3820704. doi: 10.1155/2016/3820704, PMID 26977173.

16. Winter CA, Risley EA, Nuss GW. Carrageenin-induced edema in hind paw of the rat as an assay for anti-inflammatory drugs. Experimental Biology and Medicine. 1962;111(3):544-7. doi: 10.3181/00379727-111-27849.

17. Olajide OA, Awe SO, Makinde JM, Ekhelar Al, Olusola A, Morebise O, et al. Studies on the anti-inflammatory, antipyretic and analgesic properties of Alstonia boonei stem bark. J Ethnopharmacol. 2000 Jul 1;71(1-2):179-86. doi: 10.1016/s0378-8741(99)00200-7, PMID 10904161.

18. Turner RA, Mann DE. Screening methods in pharmacology. By Robert A. Turner. J Pharm Sci. 1965. xv + 332 pp;54(9):1394:15.5 × $23.5 \mathrm{~cm}$. Price $\$ 12$

19. Tomazetti J, Ávila DS, Ferreira AP, Martins JS, Souza FR, Royer C, et al. Baker yeast-induced fever in young rats: Characterization and validation of an animal model for antipyretics screening. J Neurosci Methods. 2005 Aug 30;147(1):2935. doi: 10.1016/j.jneumeth.2005.03.002, PMID 16054514

20. Shaikh RU, Pund MM, Gacche RN. Evaluation of anti-inflammatory activity of selected medicinal plants used in Indian traditional medication system in vitro as well as in vivo. J Tradit Complement Med. 2016 Oct 1;6(4):355-61. doi: 10.1016/j.jtcme.2015.07.001, PMID 27774419.

21. Bentley GA, Newton SH, Starr J. Studies on the antinociceptive action of $\alpha$-agonist drugs and their interactions with opioid mechanisms. Br J Pharmacol. 1983 May 1;79(1):125-34. doi: 10.1111/j.1476-5381.1983.tb10504.x, PMID 6135474.

22. Ribeiro RA, Vale ML, Thomazzi SM, Paschoalato ABP, Poole S, Ferreira SH, et al. Involvement of resident macrophages and mast cells in the writhing nociceptive response induced by zymosan and acetic acid in mice. Eur J Pharmacol. 2000 Nov 3;387(1):111-8. doi: 10.1016/s0014-2999(99)00790-6, PMID 10633169.

23. Pavao-De-Souza GF, Zarpelon AC, Tedeschi GC, Mizokami SS, Sanson JS, Cunha TM, et al. Acetic acid- and phenyl-p-benzoquinone-induced overt painlike behavior depends on spinal activation of MAP kinases, PI(3)K and microglia in mice. Pharmacol Biochem Behav. 2012 May 1;101(3):320-8. doi: 10.1016/j. pbb.2012.01.018, PMID 22306747.

24. Berkenkopf JW, Weichman BM. Production of prostacyclin in mice following intraperitoneal injection of acetic acid, phenylbenzoquinone and zymosan: Its role in the writhing response. Prostaglandins. 1988 Nov 1;36(5):693-709. doi: 10.1016/0090-6980(88)90014-7, PMID 2853424.

25. Deraedt R, Jouquey S, Delevallée F, Flahaut M. Release of prostaglandins E and $F$ in an algogenic reaction and its inhibition. Eur J Pharmacol. 1980 Jan 11;61(1):17-24. doi: 10.1016/0014-2999(80)90377-5, PMID 7353582.

26. Subedi NK, Rahman SMA, Akbar MA. Analgesic and antipyretic activities of methanol extract and its fraction from the root of Schoenoplectus grossus. Evid Based Complement Alternat Med. 2016;2016:3820704. doi: 10.1155/2016/3820704, PMID 26977173.

27. Patgiri B, Umretia BL, Vaishnav PU, Prajapati PK, Shukla VJ, Ravishankar B. Anti-inflammatory activity of Guduchi Ghana (aqueous extract of Tinospora cordifolia Miers.). Ayu. 2014;35(1):108-10. doi: 10.4103/0974-8520.141958, PMID 25364210.

28. Di Rosa M, Giroud JP, Willoughby DA. Studies on the mediators of the acute inflammatory response induced in rats in different sites by carrageenan and turpentine. J Pathol. 1971 May;104(1):15-29. doi: 10.1002/path.1711040103, PMID 4398139

29. Morris CJ. Carrageenan-induced paw edema in the rat and mouse [internet]. Methods Mol Biol. 2003;225:115-21. doi: 10.1385/1-59259-374-7:115, PMID 12769480.

30. Kumar R, Clermont G, VodovotzY, Chow CC. The dynamics of acute inflammation. J Theor Biol. 2004 Sep 21;230(2):145-55. doi: 10.1016/j.jtbi.2004.04.044, PMID 15321710

31. Altman R, Bosch $B$, Brune $K$, Patrignani $P$, Young $C$. Advances in NSAID development: Evolution of diclofenac products using pharmaceutical technology. Drugs. 2015;75(8):859-77. doi: 10.1007/s40265-015-0392-z, PMID 25963327.

32. Pasin JSM, Ferreira APO, Saraiva ALL, Ratzlaff V, Andrighetto R, Tomazetti J, et al. Diacerein decreases TNF- $\alpha$ and IL-1 $\beta$ levels in peritoneal fluid and prevents baker's yeast-induced fever in young rats. Inflamm Res. 2010 Mar 3;59(3):18996. doi: 10.1007/s00011-009-0085-8, PMID 19730987.

33. Chuck B. The neurobiology of the human febrile response. ANNA J. 2006;74(2):145-50.

34. Anders B, David E. Neural mechanisms of Inflammation Induced fever Neurosci. 2018;24(4):381-99. 
35. Aronoff DM, Neilson EG. Antipyretics: Mechanisms of action and clinical use in fever suppression. Am J Med. 2001;111(4):304-15. doi: 10.1016/s00029343(01)00834-8, PMID 11566461.

36. Fan SH, Ali NA, Basri DF. Evaluation of analgesic Activity of the methanol Extract from the Galls of Quercus infectoria (Olivier) in Rats. Evid Based Complement Alternat Med. 2014;2014:976764. doi: 10.1155/2014/976764, PMID 25254062.

37. Afsar T, Khan MR, Razak S, Ullah S, Mirza B. Antipyretic, anti-inflammatory and analgesic activity of Acacia hydaspica R. Parker and its phytochemical analysis.
BMC Complement Altern Med. 2015 Apr 29;15(1):136. doi: 10.1186/s12906015-0658-8, PMID 25928288

38. Kumar A, Agarwal K, Maurya AK, Shanker K, Bushra U, Tandon S, et al. Pharmacological and phytochemical evaluation of Ocimum sanctum root extracts for its anti-inflammatory, analgesic and antipyretic activities. Pharmacogn Mag. 2015;11(Suppl 1):S217-24. doi: 10.4103/0973-1296.157743. PMID 26109769.

39. Karak P. Biological activities of flavonoids: An overview. IJPSR. 2019;10(4):1567-74.

Cite this article: Doe P, Danquah CA, Ohemeng KA, Opare AE, Sharif A, Akua-Abora D, et al. Analgesic, Anti-inflammatory, and Anti-pyretic Activities of Crinum pedunculatum R.Br. Bulb Extracts. Pharmacog Res. 2022;14(1):24-9. 